\title{
UMA EXPERIÊNCIA EDUCATIVA DE ROBÓTICA EM BAIRROS DE VULNERABILIDADE SOCIAL DE VITÓRIA DA CONQUISTA - BAHIA ${ }^{1}$
}

\author{
Andrique Figueirêdo Amorim², \\ Igor Araujo Dias Santos, \\ Luiz. Marcos Garcia Gonçalves", \\ Marcos Pereira Santos, \\ Naiara Silva dos Santos, \\ Valmir Henrique de Araújo ${ }^{7}$
}

\section{RESUMO}

O presente artigo procura descrever a primeira experiência do curso de robótica educacional, planejada para ser desenvolvida com algumas crianças e adolescentes residentes nos bairros das Pedrinhas e do Alto Maron - Vitória

\footnotetext{
${ }^{1}$ Dedicado a Jean Carlo Soares Rocha, um dos participantes de nosso curso de robótica no Centro de Extensão da UESB. Estudante de Eletromecânica do Instituto Federal da Bahia (IFBA).

${ }^{2}$ Bacharel em Ciência da Computação pela Universidade Estadual do Sudoeste da Bahia (UESB). E-mail: andrique@gmail.com

${ }^{3}$ Bacharelando de Engenharia da Computação pela Faculdade Independente do Nordeste (FAINOR).E-mail: higor@live.com

${ }^{4}$ Professor do Departamento de Computação e Automação da Universidade Federal do Rio Grande do Norte (UFRN). Doutor em Engenharia de Sistemas e Computação. Pós-Doutor na Área de Ciência da Computação. Coordenador da Pós-Graduação em Engenharia Elétrica e Computação da UFRN. E-mail: lmarcos@natalnet.br

${ }^{5}$ Bacharel em Ciência da Computação pela UESB. Professor do IFBA. E-mail: marcoscoller@ yahoo.com

${ }^{6}$ Professora de Linguagem de Programação da UESB/Jequié. Pesquisadora do Centro de Pesquisa e Desenvolvimento de Software (CPDS) - UESB/Jequié. Especialista em Ciência da Computação pela UFRN. E-mail: naiarassantos@gmail.com

${ }^{7}$ Professor Adjunto de Física. Doutor em Educação pela UFRN. Pós-Doutor em Robótica Educacional pela UFRN. Diretor do Departamento de Ciências Exatas e Tecnológicas (DCET)/ UESB. E-mail: valmirboaideia@gmail.com
}

\begin{tabular}{l|l|l|l|l}
\hline Revista Extensão \& Cidadania & Vitória da Conquista & v. 1, n. 2 & p. 53-69 & jul/dez. 2013 \\
\hline
\end{tabular}


da Conquista - BA. O curso é uma ação do projeto de extensão da UESB Alfabetização científica: Uma Perspectiva de Reconstrução Social para a Diversidade Étnicorracial. Esse projeto se propõe tanto a contribuir para a formação de professores na diversidade étnicorracial e étnico-cultural presente nas salas de aulas, quanto possibilitar uma alfabetização científica inclusiva ao se dirigir às crianças e adolescentes pertencentes a escolas localizadas nos bairros de vulnerabilidade social. Nessa perspectiva, procuramos fazer a inserção da física e da robótica nas séries iniciais do ensino fundamental, em um processo de aprendizagem que prima pela construção do conhecimento em concomitância com as (re)construções de identidade e auto-estima. A estratégia metodológica para tal objetivo é fazer uso da robótica educacional e da narrativa poética da ciência.

Palavras-chave: Alfabetização científica. Robótica educacional. Diversidade Étnica. Narrativas poéticas da ciência. Vulnerabilidade social.

\section{ABSTRACT}

This article seeks to describe the experience of the first educational robotics course, planned to be developed with some children and adolescents living in neighborhoods of the Pedrinhas and Alto Maron. The course is an action of the extension project of UESB Scientific literacy: A Perspective of Social Reconstruction Étnicorracial for Diversity. This project aims both to contribute to the training of teachers, by focusing on diversity and ethniccultural and étnicorracial in schools, and to foster an inclusive scientific literacy by addressing children and adolescents from schools located in socially vulnerableneighborhoods. From this perspective we seek to make the inclusion of physics and robotics in the early grades of elementary school, in a process of learning material for the construction of knowledge in conjunction with the (re) constructions of identity and self-esteem, to make use of robotics education and poetic narrative of science.

Keywords: Scientific literacy. Educational robotics. Ethnic diversity. Poetic narrative of science. Social vulnerability.

\section{INTRODUÇÃO}

O curso de robótica educacional é uma das ações do projeto de extensão Alfabetização científica: Uma Perspectiva de Reconstrução Social para a Diversidade Étnicorracial. A vivência aconteceu em outubro de 2011, no Centro de Extensão da UESB, localizado na Avenida Presidente 
Vargas- Vitória da Conquista - BA, e contou com o apoio da Esp. Maria Esther Pereira Flick, Prof ${ }^{a}$ MsC. Maristela Miranda Vieira de Oliveira, coordenadoras dos projetos de extensão Pedras Preciosas, Incubadora de Economia Solidária e Prof. Dr. Roque Mendes Prado Trindade, coordenador do Centro Digital de Cidadania.

A contribuição do Curso na formação de professores é que esses, enquanto estudantes de licenciatura da UESB, participam da elaboração e execução do curso. Por outro lado, ao implementar as atividades com as crianças e adolescentes, possibilitam o uso de instrumento mediadores na construção do conhecimento - por meio da robótica educacional e narrativa poética da ciência como instrumentos culturais - além de ampliarem o conhecimento como requisito para a reconstrução social, em concomitância as (re) construções de identidade e auto-estima.

\section{Fundamentação teórica}

A proposta é dar os primeiros passos de uma educação científica para a diversidade étnico-cultural nas séries iniciais do ensino fundamental, com o uso de tecnologias digitais de informação e comunicação (LOPES; FÜRKOTTER, 2009) por meio da robótica educacional (GONÇALVES et al., 2010) que inclua a construção/ reconstrução de identidade étnico-cultural das crianças e adolescentes de escolas públicas situadas nos bairros das Pedrinhas e Alto Maron, Vitória da Conquista - BA.

Para atender as expectativas do projeto de extensão citado acima, o curso de robótica, composto de oficinas ao longo de 2011, objetiva possibilitar às crianças e adolescentes dos referidos bairros, uma "alfabetização científica” (CHASSOT, 2000) que tente, concomitantemente, promover a construção de auto-estima e identidade no processo de construção do conhecimento.

Sabe-se que as dificuldades de abordagem do tema identidade são as mais diversas, no que pese as reflexões de Hall (2006), Bauman (2005), Castell (2002) e Giddens (2000). Contudo, deixaremos o 
aprofundamento dessa problemática para um trabalho de pesquisa, e aqui, procuramos nos valer das preocupações étnicas de Maia (2005), Moita Lopes (2002) e Chagas (1997). Para tanto utilizamos a robótica educacional e a narrativa poética da ciência (ARAÚJO, 2009), consideradas instrumentos culturais (VIGOTSKY, 2001) para a reconstrução social (EUGÊENIO, 2010).

A educação científica proposta nesse trabalho é parte de um amplo projeto histórico que tem discutido a criação de uma educação no Brasil que procure resgatar os valores locais e respeite a diversidade étnica e cultural (VALENTE, 2003; GOMES, 2003; MATTOS, 2003; DOMINGUES, 2009; PARÉ; OLIVEIRA; VELLOSO, 2007). Essa educação almeja um largo horizonte e coloca como ponto de partida a construção de princípios educacionais que pretendem nortear um novo modelo de sociedade calcada na solidariedade e respeito mútuo - sociedade essa que oscila, transforma-se e se deforma em face das constantes mudanças impostas pela globalização (GIDDENS, 2000; HALL, 2005, 2006; BAUMAN, 2010) - transformando as pessoas e levando-as a se empenharem a serem construtoras e reconstrutoras de suas identidades (NASCIMENTO, 2001; ROMÃO, 2001), bem como em detentoras de alta auto-estima (SOUZA, 2002; 2001a,b; ROMÃO, 2001) e auto-realização. Em face dessas transformações que atinge todas as partes do planeta e impõe uma atualização constante de conhecimento, assim como a reflexão acerca da identidade das pessoas em face das mudanças constantes, é que o curso de robótica educacional é dirigido às comunidades acima citadas.

Sabe-se que, por muito tempo, as séries iniciais do ensino fundamental tiveram a meta de fazer com que os alunos e as alunas aprendessem a ler, escrever e calcular. Esses ainda são investimentos mínimos exigidos nas aprendizagens básicas e necessárias para que os estudantes possam ingressar, enquanto sujeitos sócio-históricoculturais, do processo de conhecer no mundo letrado e compartilhar de conhecimentos cujo domínio é um dos símbolos de inclusão social. Com o decorrer dos anos, a escola passou a investir na superação 
de ser mera reprodutora de conhecimentos e costumes, e tem procurado ampliar os seus horizontes de responsabilidades ao tentar atuar na perspectiva de formar os estudantes para a cidadania com a implementação de categorias e conceitos que permitam compreender e intervir no mundo.

Nesse panorama é que a educação científica surge como um direito dos estudantes e uma exigência do século XXI para a formação da cidadania. Essa proposta exige uma educação para além da mera memorização ou aplicação tecnológica do conhecimento. Dessa forma, está, então, anunciada a postulação de uma educação integral, em que se considere a cognição, a afetividade e a contemplação da diversidade étnica e cultural de nossa sociedade para que a aprendizagem faça sentido para os aprendizes de ciência, os novos leitores do mundo, como uma componente da sua vida cultural. $\mathrm{Na}$ perspectiva dessa educação, aquele que aprende os conceitos científicos, busca formar também a sua identidade. Aquele que aprende, procurará saber se situar em sua comunidade local e global; aquele que aprende procura relacionar o aprendizado com sua história e seu cotidiano e se sente parte da humanidade na elevação de sua auto-estima.

Um princípio norteador da proposta é que o conhecimento científico só possa contribuir na formação de identidades sóciohistórico-culturais cidadãs e democráticas, se o ensino contemplar que o estudante seja um sujeito ativo na produção de seu conhecimento em um ambiente colaborativo (GONÇALVES et al., 2010), e que esse conhecimento seja percebido a partir de seu referencial ou de seu acervo cultural (ROMÃO, 2001, p. 166). Assim, é nessa perspectiva que a educação científica, voltada para comunidades de vulnerabilidade social, ao inserir o conhecimento de física nas séries iniciais do ensino fundamental por meio da robótica educacional, busca proporcionar uma aprendizagem em que a construção do conhecimento seja mediada pelos sistemas simbólicos e pelas experiências científico-pedagógicas de uma ciência que é considerada universal, mas que pode se relacionar com o contexto da cultura local, aos saberes socialmente construídos na vivência de sua comunidade. 
$\mathrm{Na}$ Bahia e, em especial em nossa região do Sudoeste da Bahia, diferentemente de outras regiões do país, as escolas públicas do ensino fundamental lidam com uma especificidade bem própria: uma diversidade étnicorracial e étnico-cultural sem visibilidade, orientada por um ensino com forte tendência ideológica de homogeneização do conhecimento em que este é apenas o científico e que se universaliza a partir do etnocentrismo. Apesar da educação regular, na maioria de nossas escolas, tentar seguir as referências formais, redigidas em diretrizes e parâmetros curriculares, é sentida a dificuldade de se fazer a ligação do conhecimento escolar com o entorno imediato, com a vivência dos estudantes, com os valores locais, além das escolas carecerem de profissionais com habilitação para aplicar as novas tecnologias. Isso porque, pelo menos no que tange ao ensino de ciências, na maior parte de nossas escolas, o conhecimento científico é transmitido em seus aspectos catequéticos, falocráticos, universalista, o que se entende por “orientação eurocêntrica” (DOMINGUES, 2009, p. 980).

Assim, o ensino de ciências tem como objetivo transmitir um conhecimento considerado verdadeiro com uma avaliação que se exige a sua reprodução tal qual se transmitiu. Esse modelo de ensino, seguido pelos professores, merece a crítica de Hall (2006, p. 334) que se coloca contra uma noção particular de conteúdo, de um sentido fixo e homogeneizado, que pode ser analisado em termos de transmissão do emissor para o receptor. Modelo esse que também é orientado pela competição para atender ao mercado de trabalho. Em contraposição, a prática pedagógica colaborativa aqui em foco, possibilitada pela robótica educacional - diferentemente da transmissão do conhecimento presente na maioria das escolas - o processo de construção do conhecimento (BORGES, 2008, p. 25-33; CERRI; TOMAZELLO, 2008, p. 71-79; SANTOS, 2009, p. 128), foi mediado por experiências simples e de fácil execução. Avaliamos esse processo tanto pela observação do modo com que as crianças interagem nos grupos (VIGOTSKY, 1993, p. 71-102), quanto pela reelaboração dos 
conceitos da física envolvidos nas experiências, segundo um modo bem particular das crianças perceberem. Nessa reelaboração dos conceitos, as crianças não precisam reproduzir o conhecimento tal qual foi ensinado, mas da forma como entenderam, elas recepcionaram. Esse modo bem particular está em consonância com Hall (2006, p. 342) que diz "sempre existirão discursos na sociedade que são os meios pelos quais as pessoas tornam significativo o mundo, dão sentido ao mundo". Para esse autor, conhecer é, pois, reelaboração de atores sociais:

Você não pode fugir do fato de que dizer algo significa desmontar uma configuração de sentido existente e começar a esboşar uma nova. [...] não existe um significado fixo único e, consequentemente, nunca poderá existir uma leitura fixa, baseada na noção de um conjunto de posições ideais-típicas (HALL, 2006, p. 349, grifo do autor).

O foco do ensino de física nas séries iniciais do ensino fundamental tem sido, na maioria das escolas, uma preparação para a abordagem dessa disciplina no ensino médio e esse, por sua vez, tem o aspecto de transmissão de informações e operacionalidade por meio de equações matemáticas (VILLANI, 1981, 1984). O início desse estudo se dá apenas no nono ano do Ensino Fundamental II ou oitava série, apesar de Schroeder (2007, p. 89) considerá-la como "o mais básico dos ramos da ciência”. E é por essa consideração que propusemos, em concordância com outros autores, a inserção da mesma nas séries iniciais por meio da robótica, em atendimento às necessidades de uma específica educação científica e inclusão digital. Contudo, admitimos que "a intenção de ensinar física para crianças das séries iniciais poderia soar estranha para alguns educadores" (DAMASIO; STEFFANI, 2008, p. 4503-2a ).

Nesse sentido, a nossa proposta é implementar uma prática pedagógica colaborativa na alfabetização científica mediada pela robótica enquanto artefato didático, pautado em referenciais epistemológicos (ARAÚJO, 2009, 2010) como formas de iniciar tal inserção da física ao adotar uma perspectiva mais ampla a respeito dos propósitos do ensino. Nessa perspectiva, poderemos identificar uma 
oportunidade singular, apoiado em Schroeder (2007, p. 89), para que as crianças desenvolvam sua auto-estima além de seu capital simbólico (DOMINGUES, 2009, p. 982) através da vivência de situações ao mesmo tempo desafiadora e prazerosa, tendo em conta as especificidades culturais da comunidade e as exigências postas à educação nesse novo século (HAMBURGUER; MATOS, 2000).

Nesse desafio, Damasio e Steffani (2008, p. 4503-3) chama a atenção para o fato de que "o ensino de física deve promover a compreensão do mundo e não iniciar a formação de um cientista”. Pois está em jogo a ludicidade de aprender a aprender, o papel do prazer e da alegria no processo de aprendizagem. Ainda assim, a ludicidade não significa mera diversão, haja vista que as crianças devem trabalhar com significados físicos, discutir e propor soluções. Para esses autores, são muitos os problemas de física que a criança não consegue explicar, por isso, é conveniente testar quais estariam ao alcance de seu estágio cognitivo.

Carvalho (1989, p.3, 61) sugere que é preciso tentar conhecer como os aprendizes de ciência pensam o mundo físico e seus fenômenos e qual a lógica adotada por elas na recepção dos conceitos.

Essa é uma das razões de fundamentarmos até mesmo o uso de artefatos nas experiências, ao modo de Arribas (1987) para que estejam ao alcance de quem as realize, e desafiá-las a resolver problemas de maneira colaborativa.

Para Schroeder (2007, p. 90), aprender ciência está para além da racionalidade cognitiva, e inclui desenvolver "seus valores pessoais, a capacidade de perseverar, de lidar com frustrações (autocontrole) e refletir sobre suas ações e expectativas, ou seja, desenvolver suas habilidades afetivas, uma vez que o aprendizado necessita de um motivador".

A relevância do projeto está na tentativa de poder contemplar o processo de conhecimento da criança como uma maneira de aprendizagem em meio à vivência de uma cultura, e não para ser testado um conhecimento imperativo, um conhecimento transmitido. 


\section{Metodologia}

A estratégia metodológica da Oficina de robótica consistiu em distribuir os estudantes em pequenos grupos, dispor as peças do robô na mesa e expor a parte de um robô para servir de modelo de construção (SILVA et al., 2008). Antes da montagem pelas crianças e adolescente, se apresentou alguns tipos de robôs, os utilizados na educação como também, vídeos de atividades sócio-educativas e as partes mecânicas e eletrônicas do robô.

Utilizamos o kit de robótica LEGO NXT MINDSTORM para que pudéssemos levar uma tecnologia para alunos do ensino fundamental da rede pública (figura 1) do município de Vitória da Conquista, a ser desenvolvida no Centro de Extensão da Universidade Estadual do Sudoeste da Bahia - UESB. O kit possibilita, de forma clara e objetiva, o estudo de diversos mecanismos que levam à exploração da área da robótica, bem como o desenvolvimento de várias habilidades nos estudantes, facilitando a conexão entre disciplinas distintas com seus conteúdos teóricos sendo aplicados de maneira prática, lúdica e educativa.

A primeira etapa da oficina consistiu em apresentar aos alunos, simplificadamente, alguns conceitos da robótica (figura 1), mostrar a utilidade dos robôs na vida das pessoas, além de explicar alguns componentes eletrônicos que compõem um robô tais como sensores, motores e controladores. Algumas analogias com o dia-a-dia dos estudantes foram mostradas com o propósito de exemplificar certas partes de um robô e comprovar o quanto a robótica está próxima da vida das pessoas e não somente na ficção científica. 
Figura 1 - Exposição de conceitos relacionados à robótica pelos

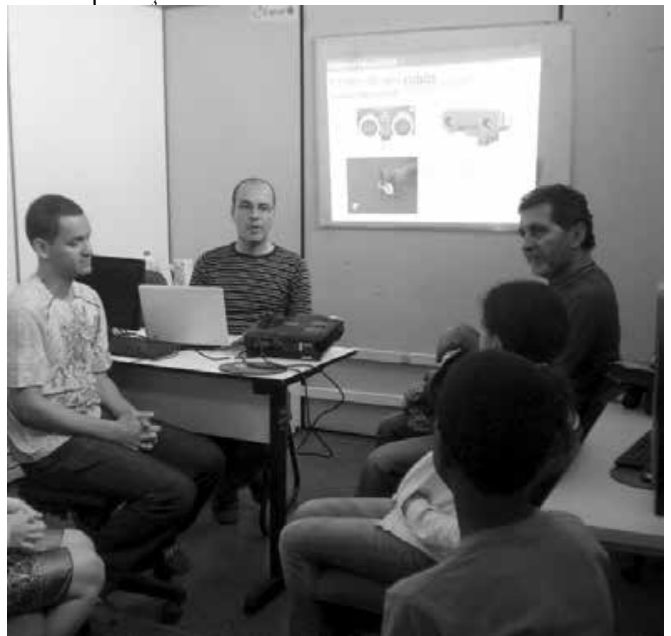

Fonte: Projeto Alfabetização Científica: Uma Perspectiva de Reconstrução Social para a Diversidade Étnicorracial.

No segundo momento, os alunos tiveram contato com um robô móvel previamente montado e programado, dotado de um sensor ultra-sônico, um sensor de toque e um sensor de cor (figura 2a).

Figura 2a - Apresentação do robô

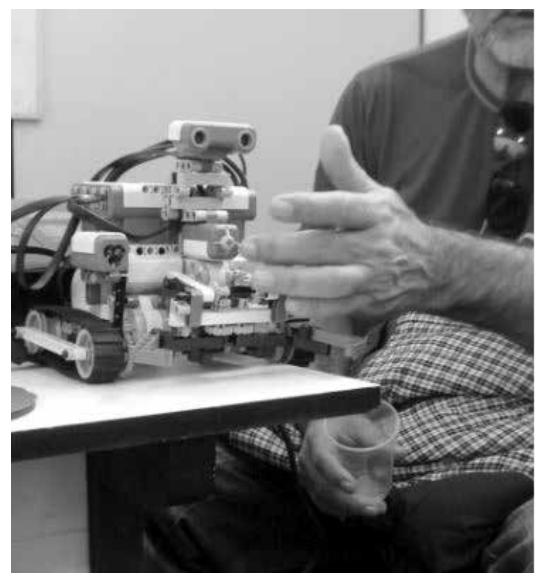

Figura 2b - Demonstração do robô

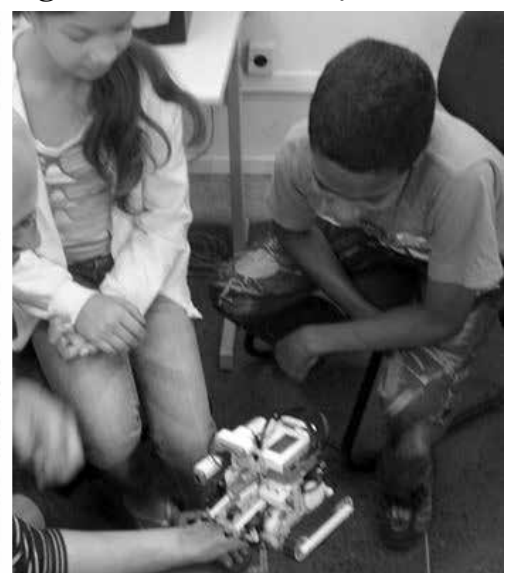

Fonte: Arquivo do Projeto. 
Nessa etapa propusemos uma demonstração prática e concreta do funcionamento de peças mecânicas e componentes eletrônicos que são capazes de, em conjunto, compor um robô que realizasse certas funcionalidades conforme percepções dos sensores e reagisse através de efetuadores (braço mecânico) e atuadores (motores).

O robô era capaz de se locomover pelo chão e desviar de obstáculos localizados a uma distância de 20 centímetros e agarrar objetos pequenos com um braço mecânico que trabalhava em conjunto com um sensor de toque. Ele também identificava cores por meio de um sensor RGB (sensor de cor) e exibia no seu visor LCD a cor do objeto que estivesse à sua frente (figura $2 \mathrm{~b}$ ).

O próximo passo foi colocar à disposição dos alunos uma parte do kit da LEGO NXT para que eles pudessem se familiarizar com o formato, encaixe e disposição das peças. Em grupos de três pessoas (figura 3), os alunos realizaram a separação das peças agrupando-as com o propósito de facilitar a localização das mesmas para a tarefa seguinte da oficina que visava a montagem de um artefato com base em um modelo.

Figura 3 - Alunos realizando a separação e organização das peças

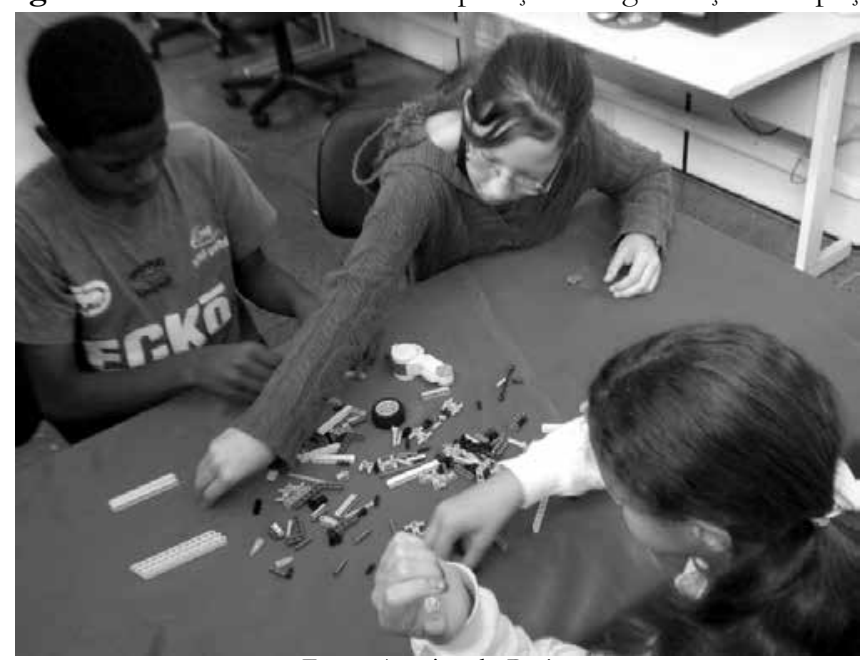

Fonte: Arquivo do Projeto. 
Nessa etapa os alunos deveriam observar o modelo proposto pelo professor e reproduzi-lo com as peças que tinham à sua disposição (figura 4). $\mathrm{O}$ artefato modelo explorava o encaixe de peças com formas e tamanhos diferentes. O objetivo foi o de perceber o nível de observação, envolvimento e colaboração na escolha das peças corretas para a montagem. O tempo da montagem foi observado, porém não se cobrou nem se estipulou um tempo aos alunos para realização da tarefa.

Figura 4 - Alunos realizando a separação e organização das peças

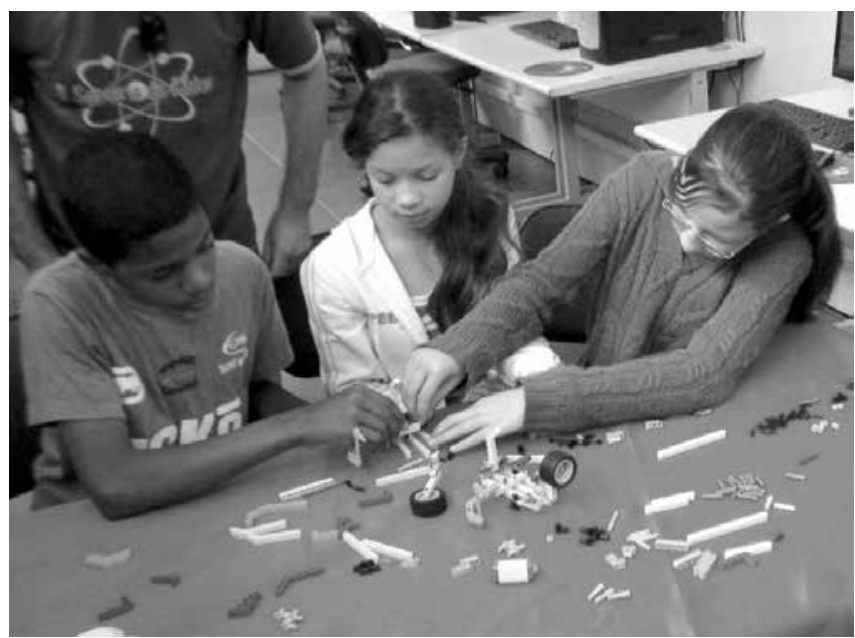

Fonte: Arquivo do Projeto.

\section{SUJEITOS}

Estudantes das séries iniciais do ensino fundamental e médio de escolas dos bairros das Pedrinhas e do Alto Maron.

\section{O ESPAÇO}

A sala de aula do Centro Digital de Cidadania (CDC), do Centro de Extensão da UESB situado na Av. Presidente Vargas, Vitória da Conquista. 


\section{Resultados obtidos}

Durante a oficina pode-se constatar que o envolvimento dos alunos, tanto na parte teórica quanto na parte prática, foi satisfatório, o que gerou expectativas de novos encontros e oficinas.

Constatou-se também, a facilidade de uso do kit LEGO NXT MINDSTORM entre crianças e jovens, em que esses foram capazes de manipular as peças sem muita dificuldade, necessitando de poucas intervenções dos professores.

O tempo para realização da montagem proposta foi considerado excelente, principalmente levando em consideração que a oficina foi o primeiro contato dos alunos com um kit de robótica.

Observou-se o trabalho em grupo e a colaboração entre os alunos durante a montagem proposta, tendo como resultado algumas manifestações individuais e pouca comunicação entre os integrantes do grupo. Mesmo assim, o objetivo da montagem foi cumprido.

\section{Considerações finais}

A oficina de robótica superou as nossas expectativas, quanto ao envolvimento dos estudantes com as tarefas nas atividades de compreensão do conteúdo da robótica, solução dos problemas propostos e na interação entre eles, um ponto importante na robótica educativa que é o processo colaborativo.

\section{Referências}

ARAÚJO, Valmir Henrique de. A narrativa poética da ciência: uma estratégia de construção do conhecimento e religação de saberes no ensino de física. 2009. Tese (Doutorado em Educação) - Universidade Federal do Rio Grande do Norte, Natal, 2009.

Alfabetização cientifica: uma perspectiva de reconstrução social para a diversidade étnicorracial. Projeto de extensão. Vitória da Conquista: UESB, 2010. 
ARRIBAS, Ir. Santos Diez. Experiências de física ao alcance da escola. 3. ed. Passo Fundo: Ed. Gráfica UPF, 1987.

BORGES, Regina Maria Rabello. Iniciação científica nas séries iniciais. In: PAVÃO, Antonio Carlos; FREITAS, Denise de (Org.). Quanta ciência há no ensino de ciências. São Carlos EdUFSCar, 2008.

BAUMAN, Zygmunt. Globalização: as conseqüências humanas. Trad. Marcus Penchel. Rio de Janeiro: Jorge Zahar, 2010.

Identidade: entrevista a Benedetto Vechi. Trad. Carlos Alberto Medeiros. Rio de Janeiro: Jorge Zahar Ed., 2005.

CARVAlHO, Anna Maria Pessoa de. Física: proposta para um ensino construtivista. São Paulo: EPU, 1989.

CASTELL, Manuel. O poder da identidade. Trad. Klauss Brandini Gerhardt. 3. ed. São Paulo: Editora Paz e Terra, 2002. v. 2.

CERRI, Yara Lygia Nogueira Sáes; TOMAZELLO, Maria Guiomar Carneiro. Crianças aprendem melhor por meio de experimentação. In: PAVÃO, Antonio Carlos; FREITAS, Denise de (Org.). Quanta ciência bá no ensino de ciências. São Carlos EdUFSCar, 2008.

CHAGAS, Conceição Corrêa das. Negro, uma identidade em construção: dificuldades e possibilidades. Petrópolis: Vozes, 1997.

CHASSOT, Attico. Alfabetização científica: questões e desafios para a educação. Ijuí: Unijuí, 2000.

DAMASIO, Felipe; STEFFANI, Maria Helena. A física nas séries iniciais $\left(2^{\mathrm{a}}\right.$ a $5^{a}$ ) do ensino fundamental: desenvolvimento e aplicação de um programa visando a qualificação de professores. Revista Brasileira de Ensino de Física, v. 30, n. 4, p. $4503,2008$.

DOMINGUES, Petrônio. O recinto sagrado: educação e antirracismo no Brasil. Caderno de Pesquisa, v. 39, n.138, set./dez. 2009.

EUGÊNIO, Benedito G. Diversidade etnicorracial e formação docente. In: LEITE, Maria Iza Pinto de et al. (Org.). Docência: gestão, ensino e pesquisa. Vitória da Conquista: Edições UESB, 2010. 
GIDDENS, Anthony. Mundo em descontrole. Trad. Maria Luiza X. de A. Borges. Rio de Janeiro: Record, 2000.

GOMES, Nilma Lio. Educação e diversidade étnicocultural. In: RAMOS, Marise Nogueira; ADÃO, Jorge Manoel; BARROS, Graciete Maria Nascimento (Coord.). Diversidade na educação: reflexões e experiências. Brasília: Secretaria de Educação Média e Tecnológica, 2003.

GONÇALVES, Luiz Marcos Garcia et al. Utilização da teoria de Vygotsky em robótica educativa. In: CONGRESO IBEROAMERICANO DE INFORMÁTICA EDUCATIVA, 9., 2008, Caracas, Venezuela. Experiencias... Caracas, Venezuela: Universidad Metropolitana, 6 a 8 mar. 2008. Disponível em: http://www.niee.ufrgs.br/eventos/RIBIE/2008/pdf/utilizacion_teoria_ vygotkski_robotica.pdf $>$. Acesso em: 16 mar. 2010.

HAMBURGUER, Ernest W.; MATOS, Cauê (Org.). O desafio de ensinar ciências no século XXI. São Paulo: Editora da Universidade de São Paulo: Estação Ciência; Brasília: CNPq, 2000.

HALL, Stuart. Da diáspora: identidades e mediações culturais. Org.: Liv Sovik; Trad. Adelaine La Guardia Resende et al. Belo Horizonte: Editora UFMG, 2006.

- A cultural na pós-modernidade. Trad. Tomaz Tadeu da Silva e Guaracira Lopes Louro. 10. ed. Rio de Janeiro: DP\&A, 2005.

LOPES, Rosemara Perpétua; FÜRKOTTER, Mônica. Tecnologias digitais de informação e comunicação (TDIC) no currículo formal dos cursos de formação de professores das universidades públicas paulistas. In: REUNIÃO ANUAL DA ANPEd, 32., 2009, Caxambu-MG, Anais Eletrônicos... CaxambuMG, 2009. Disponível em <http://www.anped.org.br/reunioes/32ra/ arquivos/posteres/GT12-5484--Int.pdf>. Acesso em: 03 mar. 2013.

MAIA, Antonio Cavalcanti. Diversidade cultural, identidade nacional brasileira e patriotismo constitucional. In: LOPES, Antonio Herculano; CALABRE, Lia (Org.). Diversidade cultural brasileira. Rio de Janeiro: Edições Casa Rui Barbosa, 2005.

MOITA LOPES, Luiz Paulo da. Identidades fragmentadas: a construção discursiva de raça, gênero e sexualidade em sala de aula. Campinas: Mercado de Letras, 2002. 
MATTOS, Wilson Roberto de. Valores civilizatórios afro-brasileiros na elaboração de currículos escolares - ensaiando pressupostos. In: RAMOS, Marise Nogueira; ADÃO, Jorge Manoel; BARROS, Graciete Maria Nascimento (Coord.). Diversidade na educação: reflexões e experiências. Brasília: Secretaria de Educação Média e Tecnológica, 2003.

NASCIMENTO, Elisa Larkin. Sankofa: educação e identidade afordescendente. In: CAVALLEIRO, Eliane (Org.). Racismo e antirracismo na educação: repensando nossa escola. São Paulo: Selo Negro, 2001.

PARÉ, Marilene Leal; OLIVEIRA, Luana Paré de; VELLOSO, Alessandra D’Aqui. A educação para quilombolas: experiências de São Miguel dos Pretos em Restinga Seca (RS) e da comunidade Kalunga do engenho II (GO). Cadernos Cedes, Campinas, v. 27, n. 72, p. 215-232, maio/ago. 2007. Disponível em: <http://www.scielo.br/scielo.php?pid=S010132622007000200007\&script=sci_arttext $>$. Acesso em: 05 dez. 2010.

ROMÃO, Jeruse. O educador, a educação e a construção de uma auto-estima positiva no educando negro. In: CAVALLEIRO, Eliane (Org.). Racismo e antirracismo na educação: repensando nossa escola. São Paulo: Selo Negro, 2001.

SANTOS, Vinício de Macedo. Linguagem e comunicação na aula de matemática. In: LOPES, Celi Aparecida Espasandin; NACARATO, Adair Mendes (Org.). Escritas e leituras na educação matemática. Belo Horizonte: Autêntica, 2009.

SCHROEDER, Carlos. A importância da física nas quatro primeiras séries do ensino fundamental. Rev. Bras. Ensino Fís., São Paulo, v. 29, n. 1, 2007.

SILVA, Alzira Ferreira da. RoboEduc: uma metodologia de aprendizado com robótica educacional. Natal, RN, 2009.

SILVA, Alzira Ferreira da et al. Utilização da teoria de Vygotsky em robótica educativa. In: CONGRESO IBEROAMERICANO DE INFORMÁTICA EDUCATIVA-RIBIE, 19., 2008, Caracas-Venezuela. Anais... CaracasVenezuela, 2008.

SOUZA, Marina de Melo e. Reis negros no Brasil escravista: história da festa de coroação de Rei Congo. Belo Horizonte: Editora UFMG, 2002. 
SOUZA, Ana Lúcia de. Negritude, letramento e uso social da oralidade. In: CAVALLEIRO, Eliane (Org.). Racismo e antirracismo na educação: repensando nossa escola. São Paulo: Selo Negro, 2001a.

SOUZA, Elisabeth Fernandes de. Repercussões do discurso pedagógico sobre relações raciais nos PCNs. In: CAVALLEIRO, Eliane (Org.). Racismo e antirracismo na educação: repensando nossa escola. São Paulo: Selo Negro, 2001b.

VALENTE, Ana Lúcia. Diversidade étnico-cultural e educação: perspectivas e desafios. In: RAMOS, Marise Nogueira; ADÃO, Jorge Manoel; BARROS, Graciete Maria Nascimento (Coord.). Diversidade na educaşão: reflexões e experiências. Brasília: Secretaria de Educação Média e Tecnológica, 2003.

VIGOTSKY, Lev Semenovich. Psicologia pedagógica. Trad. Paulo Bezerra. São Paulo: Martins Fontes, 2001.

VIGOTSKY, Lev Semenovich. Pensamento e linguagem. Trad. Jeferson Luiz Camargo. São Paulo: Martins Fontes, 1993.

VILLANI, Alberto. Considerações sobre pesquisa no ensino de física. Revista de Ensino de Física, São Paulo: Sociedade Brasileira de Física, v. 3, n. 3, p. 68-88, set. 1981.

Reflexões sobre o ensino de física no Brasil: práticas, conteúdos e pressupostos. Revista de Ensino de Física, São Paulo: Sociedade Brasileira de Física, v. 6, n. 2, p. 76-96, dez. 1984. 